This Manuscript is accepted to be published at ECAM journal DOI (10.1108/ECAM-112019-0623)

6

10

11

12

13

14

15

16

17

18

19

20

21

22

23

24

25

\title{
A CENTRALISED COST MANAGEMENT SYSTEM: EXPLOITING EVM AND ABC WITHIN IPD
}

Faris Ali Khairy Elghaish \& Sepehr Abrishami

\section{Abstract}

\section{Purpose}

Integrated Project Delivery (IPD) is highly recommended to be utilised with Building Information Management (BIM), specifically, with BIM level-3 implementation process. Extant literature highlights the financial management challenges facing the proposed integration. These challenges are mainly related to the IPD compensation and the conventional cost control approaches that are not consistent with IPD principles. As such, this paper presents an integration of several methods to support automating risk/reward sharing amongst project parties, thus, enhancing IPD core team members relationship.

\section{Design/methodology/approach}

The literature review was used to highlight the challenges that face the IPD based cost management practices such as the risk/reward sharing amongst IPD core team members, and potential methods to bridge the revealed IPD gap. A framework was developed by integrating the Activity Based Costing ( $\mathrm{ABC}$ ) - as a method to analyse the cost structure and Earned Value Management (EVM) to develop mathematical models that can determine the three main IPD financial transactions (reimbursed cost, profit and cost saving) fairly. To demonstrate the applicability of the developed system, a real-life case study was used, in which, promising results were collected in regard to visualising the cost control data and understanding of the accumulative status of the project cost and schedule for team members.

\section{Findings}

A Centralised Cost Management System (CCMS) for IPD is developed to enable the IPD cost structure, as well as, automating the risk/reward sharing calculations. This system is linked 
This Manuscript is accepted to be published at ECAM journal DOI (10.1108/ECAM-112019-0623)

with a web-based management system to display the output of proposed risk/reward sharing models. Moreover, a novel grid is developed to show the project status graphically, and to respect the diversity in core team members backgrounds. In addition, the case study showed that the proposed integration of different methods (ABC, EVM, BIM and web-based management system) is interoperable and applicable.

\section{Originality/value}

This research presents a comprehensive solution to the most revealed challenges in cost management practices in IPD implementation. The outcome of this research contributes to the body of knowledge through presenting new extensions of the EVM to be used with the IPD approach to calculate risk/reward. Moreover, the implementation of the proposed tools such as Centralised Cost Management System (CCMS) and CCMS for IPD web system will enhance/foster the implementation of the IPD in conjunction with BIM process.

Keywords: IPD; BIM; ABC; EVM; Risk/reward sharing; Cost management

\section{Introduction}

Integrated project delivery (IPD) is characterised by the early, collaborative and collective engagement of key stakeholders through all phases of delivering a project (Ahmad et al., 2019). Traditional forms of IPD, such as alliancing, can be implemented without BIM, however, new forms of IPD are defined in relation to their integration with BIM (Rowlinson, 2017), which facilitates smooth data exchange between projects' packages and parties, and in line with IPD's aims and objectives (AIA, 2007). The integration of BIM and IPD improves all likely outcomes of the design and construction process, including cost/profit, the schedule, return on investment (RoI), safety, productivity and relationships (Ilozor and Kelly, 2012). IPD relies on open pricing techniques and fiscal transparency amongst participants (Ahmad et al., 2019). In addition, project stakeholders, such as designers and contractors, typically assess and determine 
This Manuscript is accepted to be published at ECAM journal DOI (10.1108/ECAM-112019-0623)

their profit and shared risks according to the deviation between actual and target costs (AIA, 2007). However, successful delivery of a project through IPD is challenging; IPD requires fulfilling a wide range of requirements (Fischer et al., 2017). Of these requirements, the IPD compensation model, also called risk/reward compensation, is of cardinal importance (Ma et al., 2018). It is described as a key principle of IPD (Zhang et al., 2018), that plays a pivotal role in stimulating creativity, motivating collaboration, and sustaining performance (Zhang and Li, 2014a). The risk and reward must be shared and allocated to all participants in core project teams, necessitating joint project control (Fischer et al., 2017). For designing the risk and reward model (hereafter referred to as compensation approach), economic models provide a sound foundation based on the cost of projects (AIA, 2007)

The formulation of the cost structure of IPD requires significicant improvements in order to avoid hiding a profit in the estimated cost (Allison et al, 2018), to achieve the purpose of using IPD to maximise the trust amongst project parties (Ma et al., 2018). Given that risk/reward are not shared individually for IPD core team members (AIA, 2007, Pishdad-Bozorgi and Srivastava, 2018), any error in calculating the individual cost for each trade package will misestimate the profit-at-risk value of each member in IPD team. One of the main characteristics of IPD is deferring the allocation of parties' profits until all project works are completed in which brings along challenges regarding the implementation speed of IPD, since this requires all members to attend all meetings even if their works are completed at early stages of the project (Roy et al. 2018). As such, using Information and Communication Technology (ICT) is vital to share the information among parties regardless of their geographical zones.

A review of the literature shows several trends of research on the topic. Of these, a major part of the research has been allocated to exploring the potential of available tools and techniques, i.e. EVM and ABC within IPD (Hosseini et al., 2018). These studies, for the most part, stop at providing an outline of how these methods and techniques add value to the risk/reward sharing 
This Manuscript is accepted to be published at ECAM journal DOI (10.1108/ECAM-112019-0623)

mechanism in IPD (Pishdad-Bozorgi and Srivastava, 2018). BIM in integration with IPD practices are also discussed in several research studies (Fischer et al., 2017, Rowlinson, 2017, Allison et al., 2018). The challenges of such integrations are explored in another stream of studies; financial challenges, the difference in cost accounting between participants, and the lack of risk/reward sharing mechanism that can be accepted by all participants (Zahra Kahvandi, 2018). No workable methodology is however provided to demonstrate the interrelationship among BIM tools/dimensions and IPD stages in practical terms (Royet al., 2018).

To this end, the paper outlines the design of an automated model of the cost control system of IPD projects through integrating $\mathrm{ABC}$ into $\mathrm{EVM}$ to develop mathematical equations that support EVM to determine risk/reward for the owner and allnon-owner parties. The EVM is extended by a grid to allocate the output of its Cost Performance Index (CPI) and Schedule Performance Index (SPI), and subsequently, allparties can track their duties on the web system. The EVM-web system includes two kinds of reports; (1) a graphical report that shows the previous performance, as well as, the current state of the project. Each milestone is presented as a star inside the EVM grid, which is divided into four zones and each zone represents a generic case, namely; 'Optimal zone', 'Neutral Zone', 'Risk Zone' and 'Crisis Zone', (2) a metrics report that shoys three main values for owner and non-owner parties (reimbursed costs, profit and cost-saving).

\section{Information and Communication Technology (ICT) in construction management} Jacobsson and Linderoth (2010) state that the necessity of sharing a wide range of information in the construction industry leads to the necessity of utilising ICT. There are several reasons beyond calling ICT applications in the construction industry, namely, lack of integration between design and production (construction stage), facilitating the communication among 
This Manuscript is accepted to be published at ECAM journal DOI (10.1108/ECAM-112019-0623)

different disciplines (teams) whether internal (the same organisation) or across different organisations (Rahimian et al., 2008).

BIM is considered as one of the applications of ICT in the construction industry (Latiffi et al., 2013). Throughout the last decade, BIM becomes mandatory in many countries, thus the rate of adopting ICT generally has been raised (Eadie et al., 2013). ICT web-based management system is a proven tool to work efficiently and effectively in cost control tasks within the construction industry, as web system enables all project participants to see the project status easily regardless of the participant geographical zones (Ozorhon et al., 2014), forexample, Li et al. (2006) developed and tested web systems to manage and display the project performances through using EVM method. The web system is used in datamanagement in construction over the last two decades, especially, the application of Map-Based Knowledge Management (MBKM) for contractors (Lin et al., 2006) ICT in data management facilitated the understanding trough digitalising the knowledge as a map, therefore, information is presented graphically as symbols and huge data is embedded. Moreover, the makers and users can easily communicate through specific symbols, thus redundant texts will be minimised (Wexler, 2001). The research of utilising web systems in monitoring cost/schedule projects have received significant attention(Chou et al., 2010), to be more specific, utilising EVM method to display the schedule and cost simultaneously to enable stakeholders to understand and track their tasks easily (Li et al., 2006).

\section{Implications of cost management within BIM and IPD}

In moving towards efficient project delivery, the ultimate goal is having a database of information that is available to all project participants, with confidence in its accuracy, universal utility, and clarity (Oraee et al., 2017). The main drive for adopting BIM is managing all project documents and stages (i.e. design, planning, and costing) in a single/dynamic 
This Manuscript is accepted to be published at ECAM journal DOI (10.1108/ECAM-112019-0623)

context, to secure the proper exploitation of available information (Abrishami et al., 2015, Rahimian et al., 2019). BIM design elements must contain the required information in various natures, including design or management (Banihashemi et al., 2018), to acquire smartlydesigned elements, rather than traditional 3D components (Pärn and Edwards, 2017). BIM users should be capable of acquiring all the required information from a single BIM element, to make informed decisions (Elghaish et al., 2019a, Rahimian et al., 2020). Four-dimensional modelling (4D BIM) can embed progress data in 3D model objects by adjusting the task-object relationship (Hamledari et al., 2017). Application of 4D BIM leads to easily operate workflows, efficient on-site management, and assessing constructability (Hantmann et al., 2008). As for cost management, BIM is one of the most efficient Architectural, Engineering, and Construction (AEC) tools in increasing productivity on construction projects (Wang et al., 2016a). Colloquially termed as 5D BIM (Aibinu and Venkatesh, 2013), this capability of BIM offers the preferred technique for extracting quantities from 3D models, allowing cost consultants to incorporate productivity allowances and pricing values (Lee et al., 2014). The cost estimating process starts with exporting data from 3D models to BIM-based cost estimating software (e.g. CostX(B) to prepare quantity take-off. Afterwards, the Bills of Quantities (BoQ) are generated and exported to an external database (Aibinu and Venkatesh, 2013). Prices and produetivity allowances can also be added to project schedule preparation (Lee et al. 2014). Such automated quantification will shorten the quantity take-off processing time, and will automatically consider any changes in design - which is likely in fast-track projects (Wang et al., 2016a).

Cost estimation has a vital role in applying IPD (AIA, 2007, Elghaish et al., 2019a), and therefore, must be tracked through a scrutinising method by core team members to determine their profit, and shared benefits (cost saving) or risks, according to the deviation between the actual and target costs (Zhang and Li, 2014a). The compensation approach structure must be 
This Manuscript is accepted to be published at ECAM journal DOI (10.1108/ECAM-112019-0623)

capable of drawing upon effective methods, to determine cost overrun proportions, cost underrun, and any saving in the total budget under the agreed cost (Elghaish et al., 2019a). That is because, risk/reward proportion rely on the degree of achievement during the entire project stages (Pishdad-Bozorgi and Srivastava, 2018). The compensation approach has two limits; firstly, the direct, indirect, and overhead costs, which can be nominated as agreed cost, and secondly the profit-at-risk percentage after estimating the agreed cost (AIA, 2007, Zhang and $\mathrm{Li}, 2014 \mathrm{a})$. The indirect cost is defined as resources which are consumed to support activities or services, and though these resources cannot be measured in the final product, however, the entire process cannot be performed without these resources (Hastak, 2015). Meanwhile, the overhead cost is the value of needed resources for an ongoing business that contributes to the whole process rather than specific cost object (Goddard and Ooi, 1998).

The precise determination of risk perception is critical to ensure the agreed compensation structure will be implemented correctly throughout the project, so that; the risk/reward ratio can be fairly allocated among project participants. Therefore, the participant who carries more uncertain works can be compensated with higher profit-at-risk percentage (Das and Teng, 2001). Table 1 shows a summary of the revealed challenges of IPD cost management.

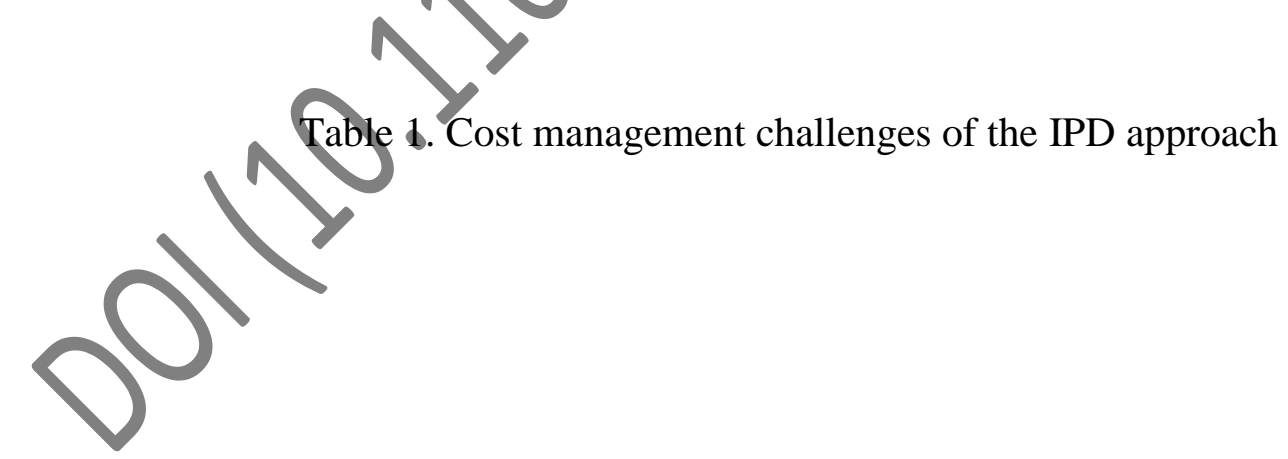


This Manuscript is accepted to be published at ECAM journal DOI (10.1108/ECAM-112019-0623)

\begin{tabular}{|c|c|c|}
\hline Stage & Challenges & References \\
\hline \multirow{3}{*}{ 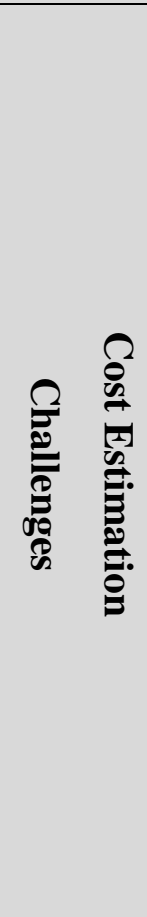 } & $\begin{array}{l}\text { The existing accounting system is unclear and } \\
\text { unreadable for all IPD core team members due to } \\
\text { having different educational backgrounds. }\end{array}$ & (Roy et al., 2018) \\
\hline & $\begin{array}{l}\text { Given that the Target Value Design (TVD) is a part } \\
\text { of the IPD approach, continuous estimation } \\
\text { feedback is needed to accomplish the pre- } \\
\text { construction IPD stages, as well as, making proper } \\
\text { decisions. }\end{array}$ & $\begin{array}{l}\text { (Allison et al., 2018, } \\
\text { Zimina et al., 2012) }\end{array}$ \\
\hline & $\begin{array}{l}\text { Given that LIMB- } 2 \text { represents the overhead cost in } \\
\text { addition to the profit at risk percentage, hereby a } \\
\text { detailed estimation technique is needed to ensure } \\
\text { that the contractor does not hide any profit into } \\
\text { overhead cost. }\end{array}$ & \\
\hline \multirow{3}{*}{ 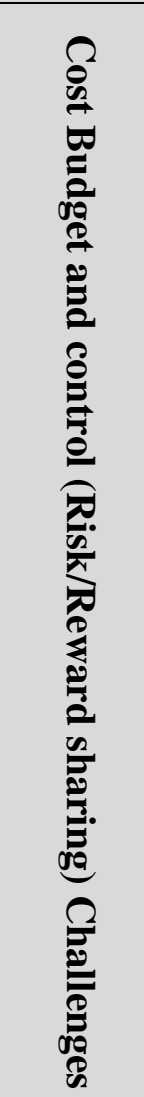 } & $\begin{array}{l}\text { Although BIM adoption can improve the traditional } \\
\text { cost/scheduling processes, however, the existing } \\
\text { budgeting systems do not consider the differences } \\
\text { between project delivery approaches. }\end{array}$ & (Lu et al., 2016) \\
\hline & $\begin{array}{l}\text { Given, the IPD approach stages do not include a } \\
\text { tender stage to select the optimal bid, therefore, a } \\
\text { methodology framework to develop a cash flow } \\
\text { system using BIM tools within documentation and } \\
\text { buyout stage is needed. }\end{array}$ & (Wang et al., 2016b) \\
\hline & $\begin{array}{l}\text { Sharing risk/reward requires an } \\
\text { automated/immutable system to record achieved } \\
\text { profit; cost-saving and reimbursed monetary values } \\
\text { for each member due to the IPD core team members } \\
\text { cannot receive their profits and rewards until all } \\
\text { project works will be delivered. }\end{array}$ & $\begin{array}{l}\text { (Zhang and Li, } \\
\text { 2014b, Ashcraft, } \\
\text { 2012) }\end{array}$ \\
\hline
\end{tabular}


This Manuscript is accepted to be published at ECAM journal DOI (10.1108/ECAM-112019-0623)

\begin{tabular}{|c|c|c|}
\hline & $\begin{array}{l}\text { "Cost and schedule are relatively easy to measure. } \\
\text { If there are early profit distributions, however, there } \\
\text { must be a method for comparing progress achieved } \\
\text { to the progress required at that milestone. This will } \\
\text { invariably involve some level of estimating using a } \\
\text { modified earned value calculation with claw-back } \\
\text { and true-up provisions" }\end{array}$ & (Ashcraft Jr, 2011) \\
\hline & $\begin{array}{l}\text { Given, all participants sharing their profit/risk } \\
\text { regardless the timeline of executing their works, } \\
\text { therefore, an automated system is required to ensure } \\
\text { that all profits and risks will move to the profit/risk } \\
\text { pools accurately. }\end{array}$ & t., 2018 \\
\hline \multirow{3}{*}{ 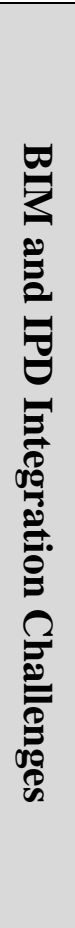 } & $\begin{array}{l}\text { IPD, TVD and BIM are regarded as a winning } \\
\text { combination for improving project delivery success. } \\
\text { However, very limited research is available to } \\
\text { validate the positive aspects of these relationships } \\
\text { by providing workable solutions appealing to } \\
\text { practitioners. }\end{array}$ & $\begin{array}{l}\text { (Pishdad-Bozorgi et } \\
\text { al., 2013, Do et al., } \\
\text { 2015) }\end{array}$ \\
\hline & $\begin{array}{l}\text { There is not a workable methodology to } \\
\text { demonstrate the interrelationship among BIM } \\
\text { tools/dimensions and IPD stages in practical terms. }\end{array}$ & $\begin{array}{l}\text { (Holland et al., 2010, } \\
\text { Allison et al., 2018) }\end{array}$ \\
\hline & $\begin{array}{l}\text { There are significant issues regarding how BIM is } \\
\text { specified, what the process should be for developing } \\
\text { BIM communication standards, and how the BIM } \\
\text { should be managed and administered. }\end{array}$ & $\begin{array}{l}\text { (Glick and } \\
\text { Guggemos, 2009) }\end{array}$ \\
\hline
\end{tabular}

EVM is a quantitative project management technique for measuring project progress, and to provide project participants with early warnings where the project is running 'over the budget' or 'behind the schedule' (PMI, 2013). Khamooshi and Abdi (2016) provided evidence of EVM being successfully applied to several real-life projects to deliver accurate cost/schedule metrics. 
This Manuscript is accepted to be published at ECAM journal DOI (10.1108/ECAM-112019-0623)

171

172

173

174

175

176

177

178

179

180

181

182

183

184

185

186

187

188

189

190

191

192

193

According to Naeni et al. (2011) "earned value technique is a crucial technique in analysing and controlling the performance of a project". EVM, as recommend by PMI (2013), is an effective tool for supplying cost and schedule indicators, to measure performance through CPR and SPR values. The granularity between project schedule, which is represented using Work Breakdown Structure (WBS), and the project cost is represented through the Cost Breakdown Structure (CBS), therefore, there is a problem in the accurate implementation of EVM (Pajares and López-Paredes, 2011). The EVM system, therefore, needs to be smarter, provided with advanced capabilities, to enable a correlation between data from multiple sources, and also, automatically generating the cost control report (Lipke et al., 2009). The interoperability issue among various data sources, to build federated project cost-control sheets, is best resolved through using advanced technologies and visualisation techniques (Chou et al., 2010). PMI (2013), is an effective tool for supplying cost and schedule indicators, to measure performance through Cost Performance Ratio (CPR) and Schedule Performance Ratio (SPR) values, according to Equation 1 and Equation 2 .

$$
\mathrm{CPI}=\frac{\mathrm{ACWP}}{\mathrm{BCWP}}
$$

$$
\mathrm{SPI}=\frac{\mathrm{BCWS}}{\mathrm{BCWP}}
$$

Where ACWP represents the actual cost of work performed, BCWP represents the budgeted cost of work performed, and BCWS represents the budgeted cost of work scheduled. The achievement values are determined in accordance with the following parameters; (1) CPI < 1 indicates that the cost performance is poor, $\mathrm{CPI}=1$ indicates that the cost performance is efficient, and CPI > 1 indicates that the cost performance is excellent. Using EVM, achievements can be measured as variance not performance, such as Cost Variance (CV) and Schedule Variance (SV), as highlighted in Equations 3 and 4. In that case, a $\mathrm{CV}<0$ indicates a 
This Manuscript is accepted to be published at ECAM journal DOI (10.1108/ECAM-112019-0623)

194

195

196

197

198

199

200

201

202

203

204

205

206

207

208

209

210

211

212

213

214

215

project over budget, a $\mathrm{CV}=0$ indicates a project on budget, and a $\mathrm{CV}>0$ indicates a project under budget (Pajares and López-Paredes, 2011).

$\mathrm{CV}=\mathrm{BCWP}-\mathrm{ACWP}$

$\mathrm{SV}=\mathrm{BCWP}-\mathrm{BCWS}$

\section{Activity Based Costing (ABC)}

Construction projects typically rely on a fragmented structure - of participants, and this fragmentation leads to an increase in overhead activities, and accordingly overhead costs (Mignone et al., 2016). There are several traditional cost accountant methods; Resource Based Costing (RBC) that relies on the resources' cost, and Volume Based Allocation (VBA) that is based on allocating the cost of resources directly to the objects, regardless of the cost structure - direct, indirect, and overhead costs (Holland and Jr, 1999). Cost distortion, however, occurs in using these traditional methods, due to conflating all indirect costs into one, which distorts the pricing of company products (Miller, 1996). ABC is a solution to such distortion, through allocating costs of multi-poots and determining the overhead activities and the associated costs needed to transform the resources into activities that can deliver the final product (Kim and Ballard, 2001). The ABC approach can measure costs based on activities and link the cost drivers to the impactmeasures of a certain product or service (Tsai and Hung, 2009). The ABC method, therefore, can improve the efficiency and accuracy of cost-related information and further monitor and control project costs (Tsai et al., 2014). This becomes particularly relevant in a collaborative working environment - like IPD - in which multiple stakeholders, beyond the control of a single company, can affect cost drivers (Kim et al., 2016). 
This Manuscript is accepted to be published at ECAM journal DOI (10.1108/ECAM-112019-0623)

216

217

218

219

220

221

222

223

224

225

226

227

228

229

230

231

232

233

234

235

236

237

The literature review was employed to highlight the research gap and build a theoretical background for proposed methods and processes such as ABC, EVM and BIM to develop a framework to enable automating IPD financial transactions. The development process commences by integrating $\mathrm{ABC}$ into EVM to develop mathematical models that can estimate the main three transactions (reimbursed costs, profit and cost saving) under various cases. A proof of concept is then developed to test the applicability, validity and practicatity of the proposed framework, the following tools were utilised:

1. Microsoft Access to develop the database, the process is strengthened using Macros and Visual Basic (VB) programming language to automate the process.

2. Caspio tool was used to develop a set of web-pages to share the data.

3. A website was developed and linked with the data server to automate/synchronise the data sharing process.

4. Given that 4D and 5D BIM are used to develop the cost plan, the proposed web-based management system will be updated at each payment milestone by the 4D and 5D BIM data to show the planned timeline - activities and planned start and end dates, as well as, the planned costs for activities. 4D and 5D BIM data will be presented as a figure at the top of the financial report and EVM-grid web pages.

The illustrative case study is selected here to conduct the validation of the proposed solution and to bridge the gap between the researcher understanding, and the target audience, and to inform users about the topic, of which, it was previously presented — or widely utilised (Fairley et al., 2005).

\section{Developing the framework}

The development of the framework is divided into three sections; the first section is to build a robust cost structure of IPD based on $\mathrm{ABC}$, using a proposed CCMS. The second section is to 
This Manuscript is accepted to be published at ECAM journal DOI (10.1108/ECAM-112019-0623) develop an EVM based ABC mathematical formulas to determine risk/reward values. This will enable determining the three financial transactions (Reimbursed costs, profit, and cost-saving properly). The third section is how BIM and web-based information system can be utilised.

\subsection{Centralised Cost Management System (CCMS) for the IPD approach}

CCMS is a cost management system that is developed to bridge the gap in IPD cost management practices. Figure 1 shows the user interface of this system.

\section{CCMS tasks}

\begin{tabular}{|c|}
\hline LIMB-1 (Direct_Indirect Costs) Calculations \\
\hline LIMB-2 Overhead cost calculations \\
Budget metrics \\
\hline Compensation Structure Calculations \\
\hline Financial Report
\end{tabular}

Figure 1. The user interface of the CCMS for the IPD approach

Figure 2 shows snapshots of the database structure of each table. Tables are designed using MS Access, and all processes is automated using "Macros" and VB programming. Each table includes a set of lookup fields to make the database system user-friendly through choosing from pre-defined fields, since the adoption of $\mathrm{ABC}$ in cost estimation is not widely available within the AEC industry. The interrelationships between the tables in figure 2 are designed according to the integration of EVM into ABC. Each table represents a limb in the IPD cost structure (direct, indirect, and overhead cost), as well as, the profit-at-risk percentage. This is an integrated database, which means that any change will be reflected automatically on the server, and subsequently, these data will be displayed on the web interface through converting all the data as interactive web pages.

The compensation structure in IPD relies on distinguishing direct and overhead cost, such that, owner and non-owner parties can manage their activities in accordance with their achievements in each Limb. Therefore, ABC is adopted in this research, so the cost estimation should be 
This Manuscript is accepted to be published at ECAM journal DOI (10.1108/ECAM-112019-0623) estimated and recorded within the $\mathrm{ABC}$ sheet (see table 2 in figure 2). Given that BIM is highly recommended to be coupled with IPD for successful project delivery (Allison et al., 2018), table 2 in figure 2 shows how the $\mathrm{ABC}$ sheet can be implemented within the BIM platforms (i.e. Autodesk Navisworks). In this research, the direct and indirect costs are determined as a summation of costs of direct activities, and the overhead costs are estimated as a summation of costs of overheard activities, for each trade package, all from the ABC estimation sheet. The reason behind using $\mathrm{ABC}$ for articulating the compensation approach is its capability to measure the degree of savings for each participant, which accordingly leads to effective and precise computation of the risk/reward sharing ratio (See figure 2, table 2; 'Automated ABC sheet to estimate the overhead cost'). Furthermore, the cost-saving share for owner differs from the non-owner participants, given the difference between the cost overhead saving in the organisation sustaining level and project level. Therefore, the goal of participants sharing the risk/reward ratio using this approach is to ensure equitable and a more applicable approach.

Figure 2 shows the tables that have been designed to show the data in specific sets. Table 1 is designed to estimate LIMB 1 (direct and indirect costs) using 5D BIM, meanwhile, Table 2 is developed based on the ABC to estimate the overhead costs, which is designed using automatic codes to facilitate collecting data during the construction stage. Thereafter, LIMB 2 will be automatically calculated for each party (construction package) and for the entire project (see table 2 in figure 2) All fields in this sheet will be automatically calculated according to the developed mathematical equations 5 to 16 . Subsequently, the IPD compensation structure is presented in a table entitled 'Package Costs', that include the proportions of each limb for each party in the project (see table 3, figure 2). A table is designed to estimate the financial outcome of each payment milestone is called 'Financial report', (See table 4, figure 2). 
This Manuscript is accepted to be published at ECAM journal DOI (10.1108/ECAM-112019-0623)

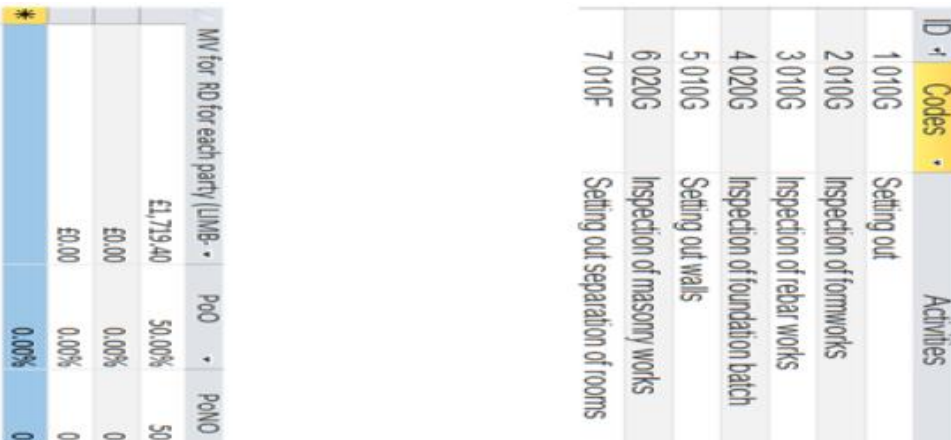

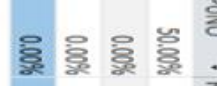

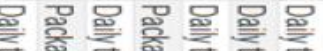

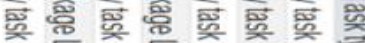

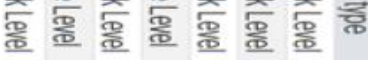

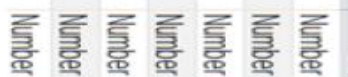
은윽응을을을응

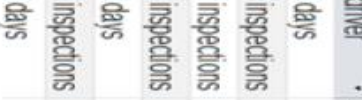

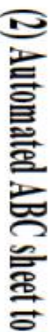

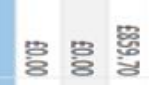
:

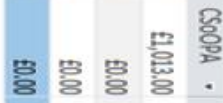
홀 훙 웅 흏

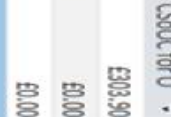

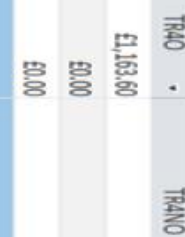

\section{客总总}

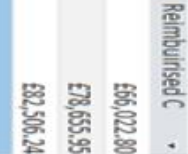

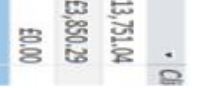

Figure 2. The structure of the database tables of the CCMS 
This Manuscript is accepted to be published at ECAM journal DOI (10.1108/ECAM-112019-0623)

\subsection{Developing EVM based ABC extensions}

A set of mathematical formulas based on EVM and $\mathrm{ABC}$ (in order to determine the risk/reward values for the owner and non-owner parties) is developed to provide the due reimbursed costs, cost-saving, and profit for owner and non-owner parties. As can be seen in equations 10, 11 and 12 , there are models to determine the cost saving, reimbursed costs, and profit. Hence, this will enable automating the payment process through coding these models in the CCMS. This could speed the rate of adopting IPD for successful project delivery by enhancing the transparency and trust among IPD core team members.

An EVM grid is developed to display the outcome of EVM's CPR and SPR, which divides the project into four zones (see figure 3), where each zone represents a đifferent case. Through allocating potential project cases on the grid, whilst conşidering $\mathbf{X}$-axis as the schedule and the Y-axis as the cost, each zone is then divided into small squares around the planned point. The main four zones are; (1) the cost and schedule outcomes are positive; this case is the optimal one. In this research, the cost is assumed as a critical parameter, therefore, (2) when the cost is positive and schedule is negative, the case is called neutral, however, if the outcome of the schedule performance is significantly negative, the accumulative parameter will be very close to the risk zone. Similarly, (3) if the cost performance is negative and schedule performance is positive, this zone according to the mentioned assumption will be the risk zone, and (4) the crisis zone is when the outcome of both cost and schedule are negative.

The user should determine the value of the CPR and SPR and enter them into the grid as a positive or negative percentage to determine the project situation at each milestone or for each package. Furthermore, the quantity surveyor marks the square in accordance with CPR and SPR percentages, to determine the cumulative progress throughout the project execution stages. Thereafter, the 'Profit-at-Risk' percentage will be shared in accordance with the output of the developed EVM-Based IPD grid. 
This Manuscript is accepted to be published at ECAM journal DOI (10.1108/ECAM-112019-0623)

Elghaish et al. (2019b) developed a risk/reward sharing model for the IPD approach. This model has been extended in this research by empowering the automation process. Since the mentioned model relies on applying a set of the equation according to the outcome of the EVM, the extended model in this research works without needing to follow any instructions. Therefore, the user will be enquired to provide the Earned Value Outcome (EVO) and other cost value, and subsequently, the profit, cost-saving, and reimbursed cost will be determined automatically in the CCMS.

The proposed models are based on EVM and ABC in order to provide the proper risk/reward sharing for all potential scenarios are presented in equations 5 to 16

- Equations 5 shows the EVO that represents the schedule and cost performances. Meanwhile, Equation 6 is the adjusted EVO with considering the P@R\% since this shows whether the performance greater or less than the $\mathrm{P} @ \mathrm{R} \%$, subsequently, determine the project case. Equation 7 is another adjustment to decide whether there is a cost saving (Reward) or not. This equation is structured as a conditional equation, so that if the Adjusted EVO $\cong 0$, the results will be the value of the adjusted EVO, otherwise, the value will be-zero.

- After determining the project case, equations 8, 9 and 10 are developed to determine the value of achieved rewards in the direct and indirect costs, equation 8 is developed to determine the total value of the reward in case that there is a cost saving in the direct and indirect costs. Then equations 9 and 10 are developed to calculate the proportions for owner and non-owner parties.

- Equations 11 and 12 are developed to determine the cost saving for overheard costs based on $\mathrm{ABC}$ sheet. For more details about the cost estimation sheet for overhead cost see table 2 in figure 2. 
This Manuscript is accepted to be published at ECAM journal DOI (10.1108/ECAM-112019-0623)

- Equations 13 and 14 are developed to calculate the summation of the reward for owner and non-owner parties for direct, indirect and overhead costs.

- Equation 15 is to calculate the reimbursed costs according to the project case; therefore, it is designed as a conditional equation according to the EVO4Profit, and two subequations are designed to determine the reimbursed costs if the EVO4Profit $>0$ and another if EVO4Profit $<0$.

- Equation 16 is developed to determine the profit as a conditional equation according to EVO4Profit value against the $\mathrm{P} @ \mathrm{R} \%$, inside this equations, two sub-equations are developed, one in case that the entire LIMB-3 (Profit) will be paid and another in case that a part of it has been consumed as a cost.

$E V O=([C P I] *[S P I])$

Where EVO represents Earned Value Outcome

Adjusted EVO $=[P @ R$ per $]-(1-[E V O])$

EVO4Profit $=\operatorname{IIf}([$ Adjusted EVO $] \geqslant=0,[$ Adjusted EVO $], 0)$

Where EVO4Profit is Earned Value Outcome for Profit

$M V$ for $R$ for each party $(L M B-1)$

$$
\begin{aligned}
& =I I f([\text { EVO4Profit }] \\
& >[P @ R \text { per }],([\text { PLIMB }-1]-[\text { Actual LIMB }-1]), 0)
\end{aligned}
$$

Where MV for R for each party (LIMB-1) represents Monetary Value for Reward for each owner and non-owner parties and LIMB-1 is the direct and indirect cost.

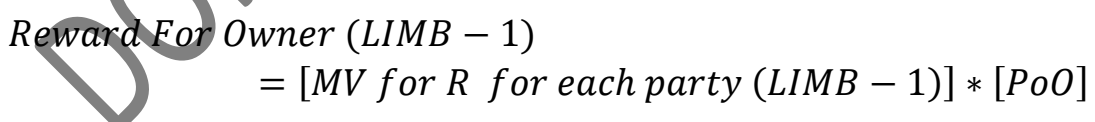

Reward For non - Owner $($ LIMB - 1)

$$
=[M V \text { for } R \text { for each party }(L I M B-1)] *[\text { PoNO }]
$$

Where PoNO or PoO is The Proportion of sharing cost-saving for Non-Owner Parties/ Owner

CSOOC for $N O=([C S O O O A]+([C S O O P A] *$ NoARP $))$

CSoOC for $O=([C S o O P A] *[O A R P])$ 
This Manuscript is accepted to be published at ECAM journal DOI (10.1108/ECAM-112019-0623)

Where CSoOC for NO represents Cost Saving of Overhead Cost for Non-Owner parties, CSoOOA represents Cost Saving of Overhead Organisation Activities, CSoOPA represents

Cost Saving of Overhead Project Activities and NoARP/ OARPis the Non-Owner/Owner Agreed Reward Percentage.

$T R 4 O=([$ Reward For Owner $(\operatorname{LIMB}-1)]+[$ CSoOC for O $])$

TR4NO $=([$ Reward For non - Owner parties $($ LIMB -1$)]+[$ CSoOC for NO $])$

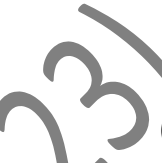

Where TR4O/TR4NOTotal Reward for Owner/Non-Owner parties.

\section{Reimbursied Cost}

$$
\begin{aligned}
& =I I f([\text { EVO4Profit }] \\
& >0,([\text { TCS }]
\end{aligned}
$$$$
-([\text { Profit }]+[M V \text { for } R \text { or } R D \text { for eachparty }(L I M B-1)]+[C S o O C \text { for } N O]
$$$$
+[\text { CSoOC for O }])),(([\text { TCS }]-[\text { Profit }])+[\text { DC above TCS }]))
$$

$$
\text { Profit }=I I f([\text { EVO4Profit }]>=[\text { P@R per }],[\text { LIMB }-3],([\text { EVO4Profit }] * 10 *
$$

$[\operatorname{LIMB}-3]))$

\section{Where TCS represents Total Compensation Structure}

\subsection{Developing an interactive web interface to display the project data}

The web-based management system is developed in six web pages, Figure 3 and 4 shows three pages which represents three functional pages (cost estimation and budgeting page - image 1 in figure 4, financial report and graphical report is presented in figure 3). Other three pages are not functional and depicted in figure 5, such as 'Home' page that includes information about the purpose and the mechanism of this platform, 'About' page that is designed to include information from the framework, in order to demonstrate how the cost estimation, budgeting, and control tasks are developed. Flowcharts in 'About' page regarding cost estimation, budgeting and control processes are presented in relevant research such as Elghaish et al. (2019a), Elghaish et al. (2019b) and Elghaish et al. (2020). Moreover, the profiles of IPD core 
This Manuscript is accepted to be published at ECAM journal DOI (10.1108/ECAM-112019-0623)

395

396

397

398

399

team members are presented on 'Project parties profiles' page, see figure 5. The description is provided to guide the IPD core team members, therefore, providing a source of information about all the cost management tasks, including the proposed risk/reward models, in which it increases the transparency and the trust amongst the IPD core team members.

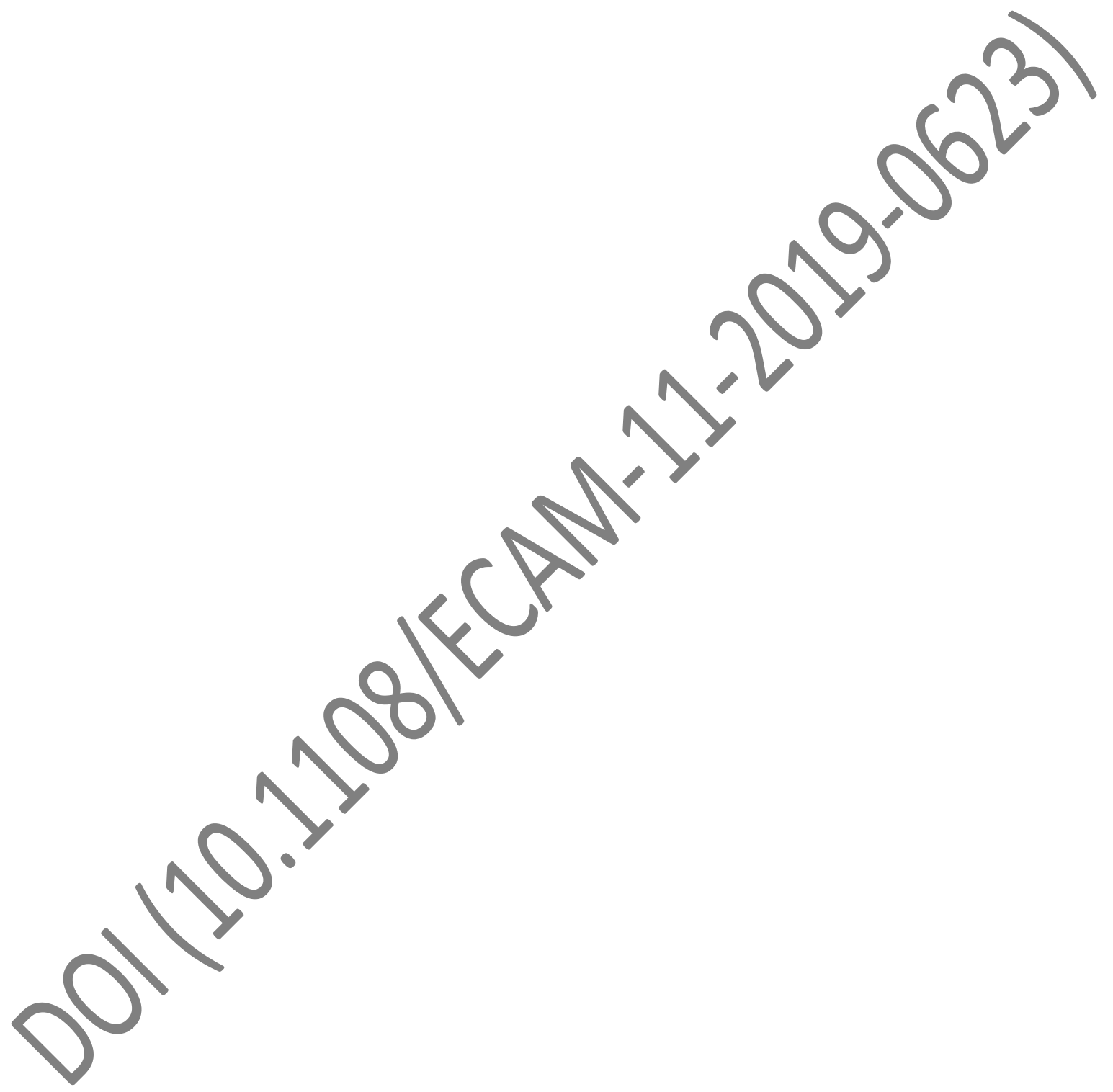


This Manuscript is accepted to be published at ECAM journal DOI (10.1108/ECAM-112019-0623)

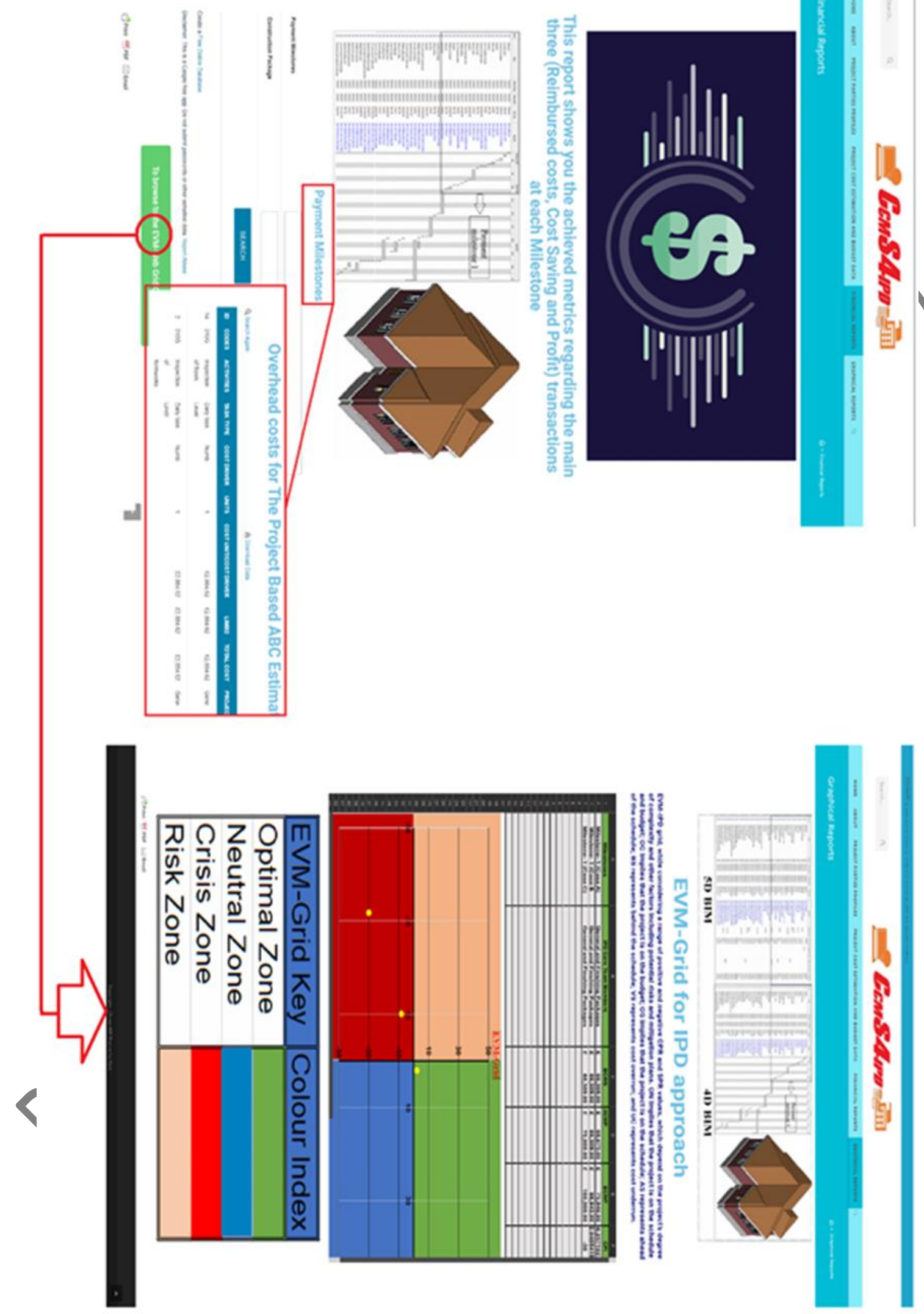

401 Figure 3. The financial report pages 
This Manuscript is accepted to be published at ECAM journal DOI (10.1108/ECAM-112019-0623)

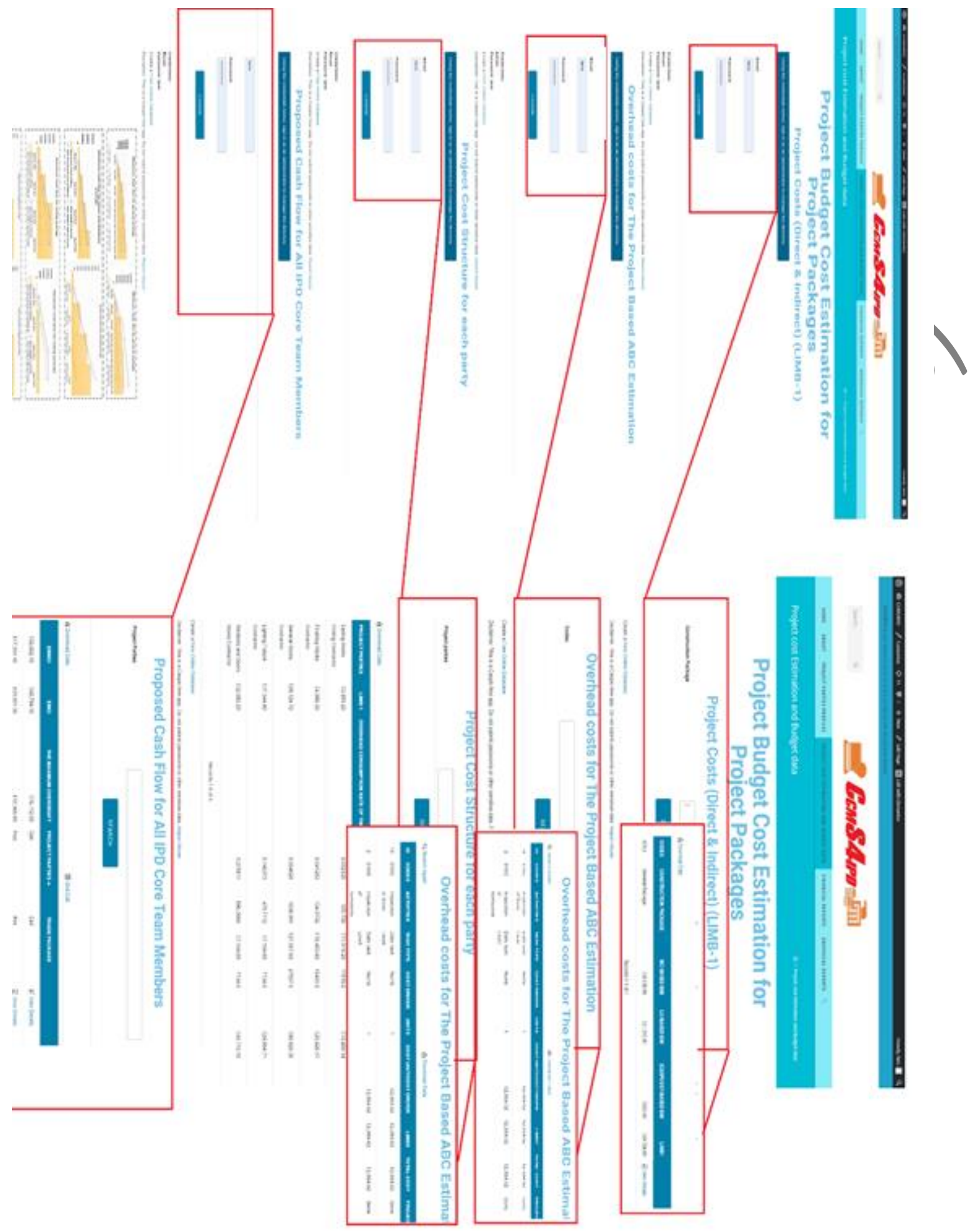

402

403 Figure 4.The cost management contents of CCMS4IPD 
This Manuscript is accepted to be published at ECAM journal DOI (10.1108/ECAM-112019-0623)

405

406

407

408

409

410

411

412

413

414

415

416

417

418

419

420

421

422

423

424

425

426

427

428

429

Given that the IPD core team members can be altered, such as adding new members while the project is progressing, or some members might finish their works at an early stage in the construction phase, the profile of all members should be updated to facilitate the contact amongst project parties (see figure 5, image 3). Moreover, this will be a source of acquaintance for future collaboration, since building sustainable relationships is one of the objectives of adopting the IPD approach.

As mentioned, there are three pages to display and manage the cost management data, including cost estimation, budget, and the risk/reward for each party, based on the EVM outcome (see figure 3). The data is stored on a server (MS Access database, figure 2 shows the database tables that are developed to store the cost estimation, budgeting and control data) and is linked as a web page through using a 'Casipo' platform. Simultaneously, the data is embedded as HTML into the web page, which enables the automated update for all data without any human interference. Figure 4 shows a snapshot of the cost estimation and budgeting tasks for IPD in three forms, namely, Limb-1 (direct and indirect costs), Limb-2 (ABC sheet for estimating the overhead costs), the cost structure of each trade package in the project (the cost-plus $\mathrm{P} @ \mathrm{R} \%$ ) and the budgeting values including the estimated minimum and maximum cash inflow. The web page is designed to enable searching in the database using different parameters, such as the construction package for Limb-1, the code and project parties for Limb-2, the project parties for Limb-3. This will enable all parties to get the specific data they require, and in a swift and organised way, regardless of their attendance to the regular IPD core team members meeting. Moreover, the readability of the data is considered to allow any party from various background to understand the structure of the data. In order to ensure the privacy and credential to such sensitive data, like costing data, authentication information (Username and password) is required before displaying any data (see figure 4), the usernames and passwords will be specified/provided by the server admin. 
This Manuscript is accepted to be published at ECAM journal DOI (10.1108/ECAM-112019-0623)

430

431

432

433

434

435

436

437

438

439

440

441

442

443

444

445

446

447

448

449

450

451

452

453

454

Figure 3 depicts the financial metrics web page for each party, by showing the 4D/5D BIM data. Each party can search using the name of the 'Package' (i.e. General Package) to show the financial metrics for different payment milestones. The financial metrics show three main transactions (Reimbursed Costs, Cost Saving, and Profit). Given that the profit/risk should be shared regardless of the individual performance, the achieved values of the three financial transactions will be presented individually to maximise the trust and collaboration amongst the IPD core team members without needing to attend the regular meetings and the generic values of the three transactions to show the progress of the project. Therefore, the proposed equations (1 to 12 ) as a result of integrating $\mathrm{ABC}$ into EVM to develop risk/reward sharing models of the IPD are presented in a web page to show the outcome of each payment milestone (see figure 3). The report can be retrieved by each party by log-in usmg the username and password provided by the server manager. Each party uses the agreed packages' names to see achieved financial metrics for both individual parties and the accumulative of all achieved works. The parties can share their report with their employees by using the embedded feature in the webpage header, which is to email the data on the page to anyone without needing to have the authentications information.

\section{N}

Given that the IPD core team members come from different backgrounds, the visualisation of data could enhance the collaboration and understanding amongst the team. Figure 3 shows a snapshot of the web-data page of the EVM-grid by showing the calculation parameters. To ensure the security of the data, the party will be asked to provide the given username and password and are able to share the data with their employees.

The presented six web-data pages works as IPD big room (ref), that is recommended by the IPD developers, to facilitate the collaboration/coordination through the greater team, specifically, when the decision is not dominant such as the IPD case. All the data regarding the cost, risk/reward values will be updated directly once it is ready, as well as, the web-based 
This Manuscript is accepted to be published at ECAM journal DOI (10.1108/ECAM-112019-0623)

455 management system is designed to serve in different stages of the IPD. During the buyout and 456 documentation stages, the web page "Project Cost Estimation and Buyout Data", the required 457 data to make the decisions are presented.

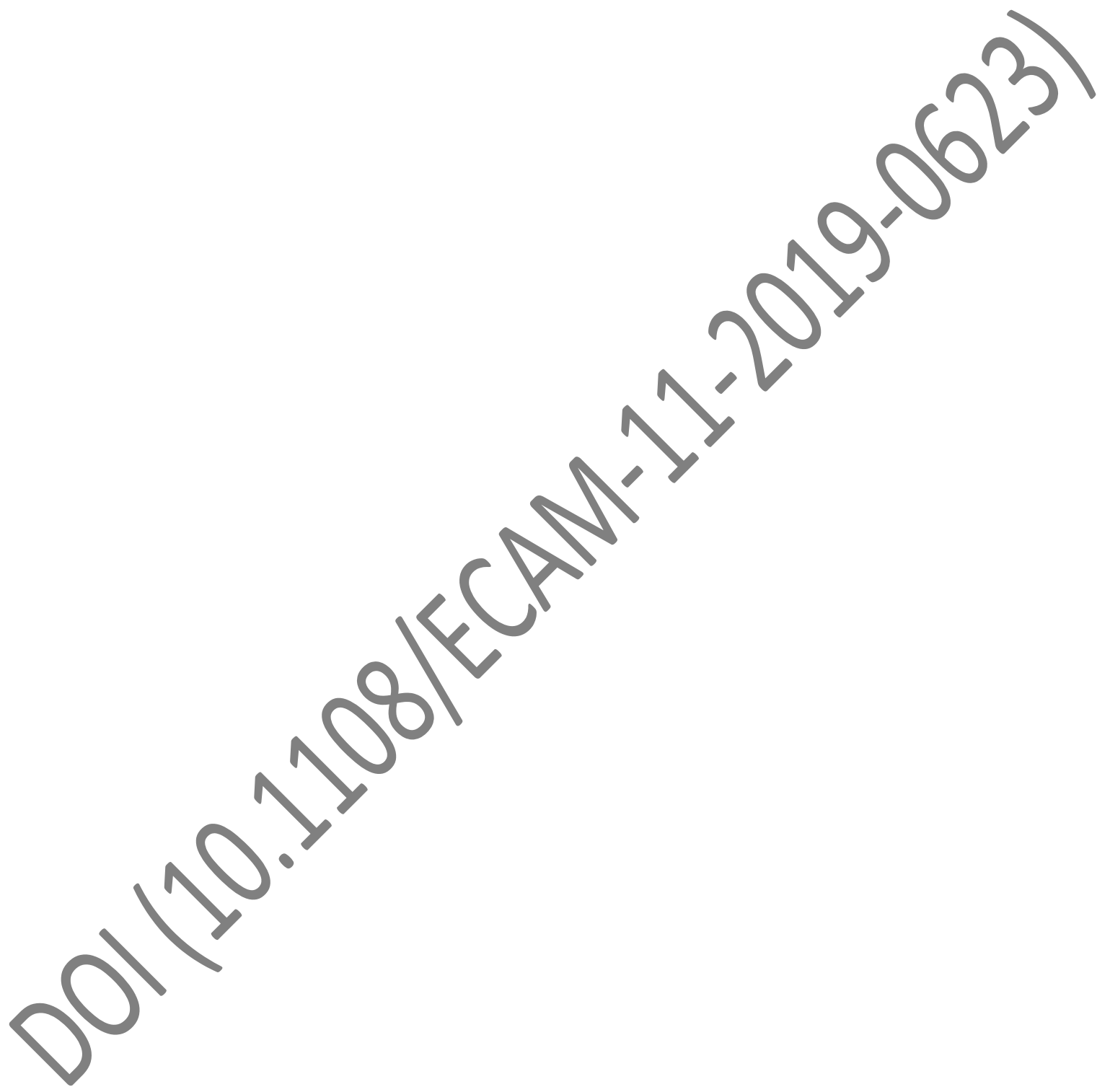


This Manuscript is accepted to be published at ECAM journal DOI (10.1108/ECAM-112019-0623)
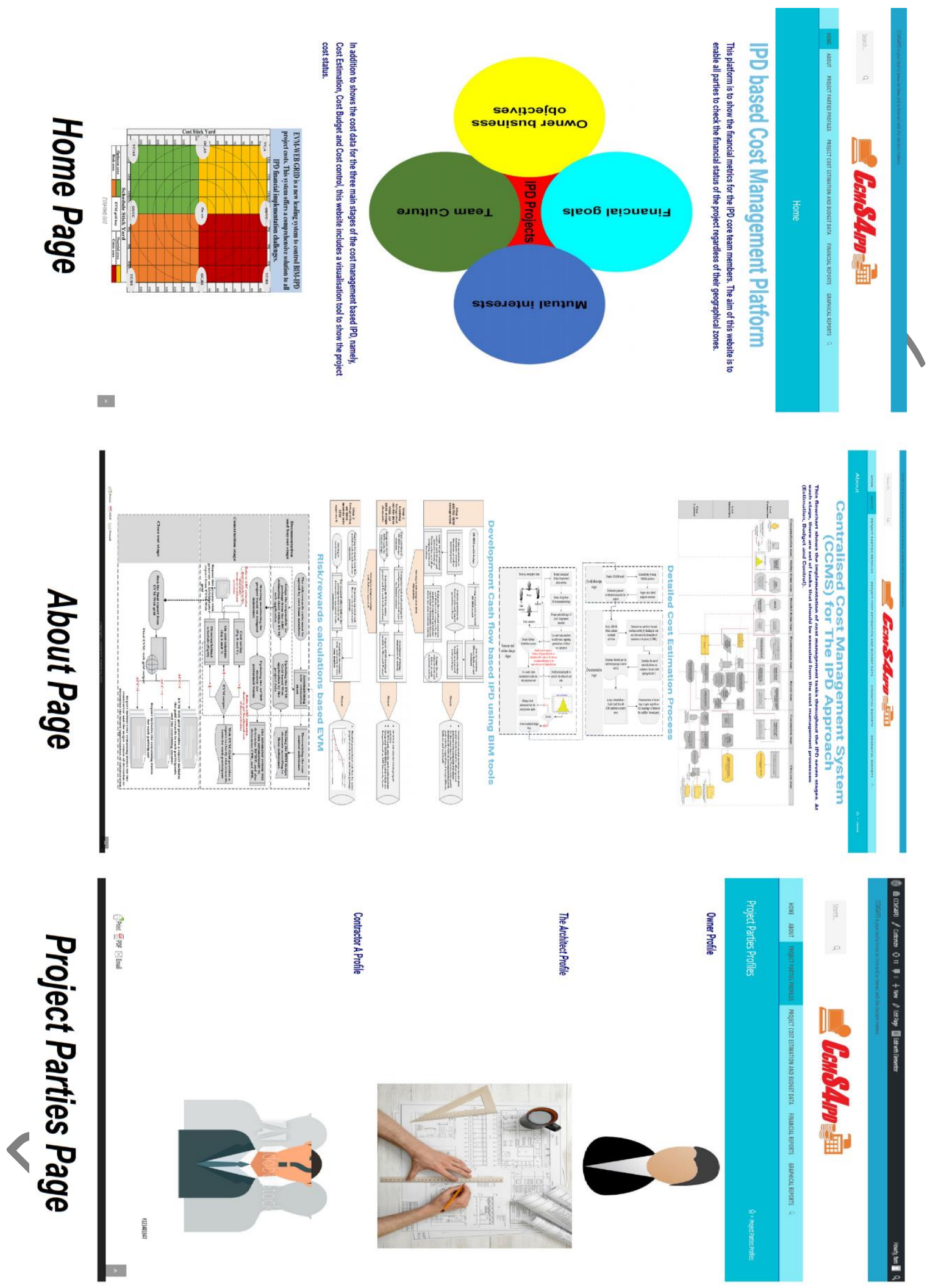

Figure 5.The CCMS4IPD non-data pages

8. Validation and result analysis 
This Manuscript is accepted to be published at ECAM journal DOI (10.1108/ECAM-112019-0623)

462

463

464

465

466

467

468

469

470

471

472

473

474

475

476

477

478

479

480

481

482

483

484

485

486

To validate the proposed methodology, the model was applied to a case study; a property development company, whose managers decided to build a new house. The costs of implementing IPD can be determined from the conceptualisation stage to buyout stages. The compensation structure was agreed upon as follows; (1) the agreed profit-at-risk percentage was $20 \%$, (2) the saving cost allocation percentage for overhead project-level cost was $70 \%$ for non-owner participants and 30\% for owner, (3) the non-owner risk/reward ratio was $80 \%$ and $20 \%$ for owner party. Although within the existing IPD model, the owner does not get any proportion from P@R\% (Limb-3), however, in this case study, it is assumed that the owner gets a proportion from $\mathrm{P} @ \mathrm{R} \%$ for two reasons; providing any seryice such as participating in managing project workflow and showing capabilities of the presented framework to work on various scenarios. (4) the direct and indirect cost limit (Limb 1) was £118,484.9; (5) Limb 2, which involved direct, indirect, overhead costs was £190,484.9; and (6) Limb 3, which comprises from the total cost and the profit-at-riskpercentage, which was $£ 228,581.9$.

\subsection{Determining the reimbursed costs, cost-saving and profit for different project} scenarios.

Figure 6 and 7 show the outcome of three scenarios of the project performance, the three scenarios are (1) when the project on budget/schedule or there is cost overrun/behind schedule, however, the P@R\% is not consumed totally, (2) when the parties achieved cost saving, , (3) the $\mathrm{P} @ \mathrm{R} \%$ is consumed totally and only the non-owners parties will receive their costs only.

Figure 6 shows the first Scenario, where, the project is located in the crisis zone as the EVO is 0.82, as well as, the CPI and SPI are 0.9 and 0.92 respectively. Therefore, there is no reward for both owner and non-owner parties. However, there is a remaining proportion of the profit since the $\mathrm{P} @ \mathrm{R} \%$ is $20 \%$ and the EVO is 0.82 , accordingly, the profit percentage is not fully consumed. and the actual reimbursed cost is more than planned. According to IPD principles, profit will not be paid to non-owner parties at each milestone payment, this amount of profit 
This Manuscript is accepted to be published at ECAM journal DOI (10.1108/ECAM-112019-0623)

487

488

489

490

491

492

493

494

495

496

497

498

499

will be kept in the profit pool till the end of the project. Meanwhile, Figure 7 shows the outcome of the other two scenarios; for the second scenario, the CPI and SPI are 1.02 and 1.02 respectively, and the EVO output was $104 \%$, located in the green area, implying an optimum situation due to the considerable positive deviation from the planned values. Therefore, three transactions should be presented — reimbursed cost, profit and cost saving. The only reimbursed cost will be paid to non-owner parties; however, profit and cost saving will be kept in profit and cost saving pools until all project works will be performed (seefigure 7,image 1). Regarding the third scenario, the EVO was 0.49 due to CPI and SPI were 0.7 and 0.7 respectively, therefore, only the reimbursed cost is presented in image 2, figure 7. Although the reimbursed cost is more than planned, this should be paid to the trade contractor according to IPD principles and this additional cost can be covered from the profit and cost saving pools as long as the needed additional cost is available in these pools, otherwise, the owner should pay the direct cost.

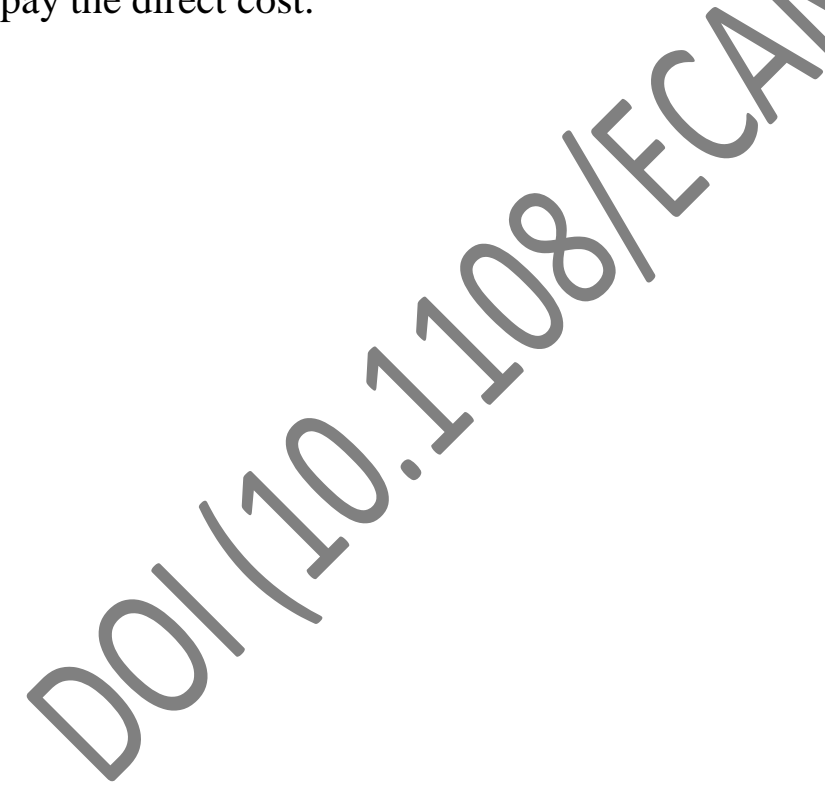


This Manuscript is accepted to be published at ECAM journal DOI (10.1108/ECAM-112019-0623)

This report shows you the achieved metrics regarding the main three (Reimbursed costs, Cost Saving and Profit) transactions at each Milestone

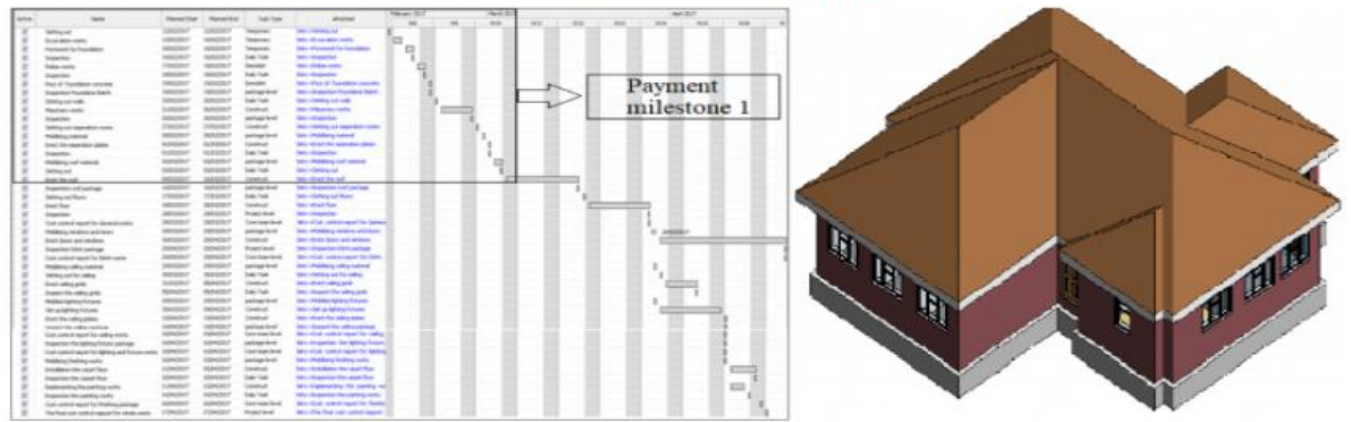

Payment Milestones

国 Report

Payment Milestones

Construction Package

Project Case

NOARP

OARP

PQR per

CPI

SPI

EVo

Adjusted Evo

EVO4Profit

Actual LIMB-1

Actual LIMB-2

PLIMB-1

PLIMB-2

LIMB-3

TCS

MV for R or RD for each party (UMB-1)

PoO

PONO

Reward For Owner (LIMB-1)

Reward For non-Owner parties (LIMB-1)

Gene and Fin

Crisis Case

0.7

0.2

0.92

09

0.82

0.028

0.028

0.028
50.00

$£ 46.332 .10$

$\mathrm{C} 22,423.10$

$\$ 13.751 .04$

582,50624

50.00

60.00

$£ 0.00$

CSOOOA

CSOOPA

CSOOC for NO

CSoOC for $\mathrm{O}$

TRAO

TRANO

Reimbuirised C

Profit

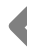

Figure 6.The risk/reward report for scenario 1 
This Manuscript is accepted to be published at ECAM journal DOI (10.1108/ECAM-112019-0623)

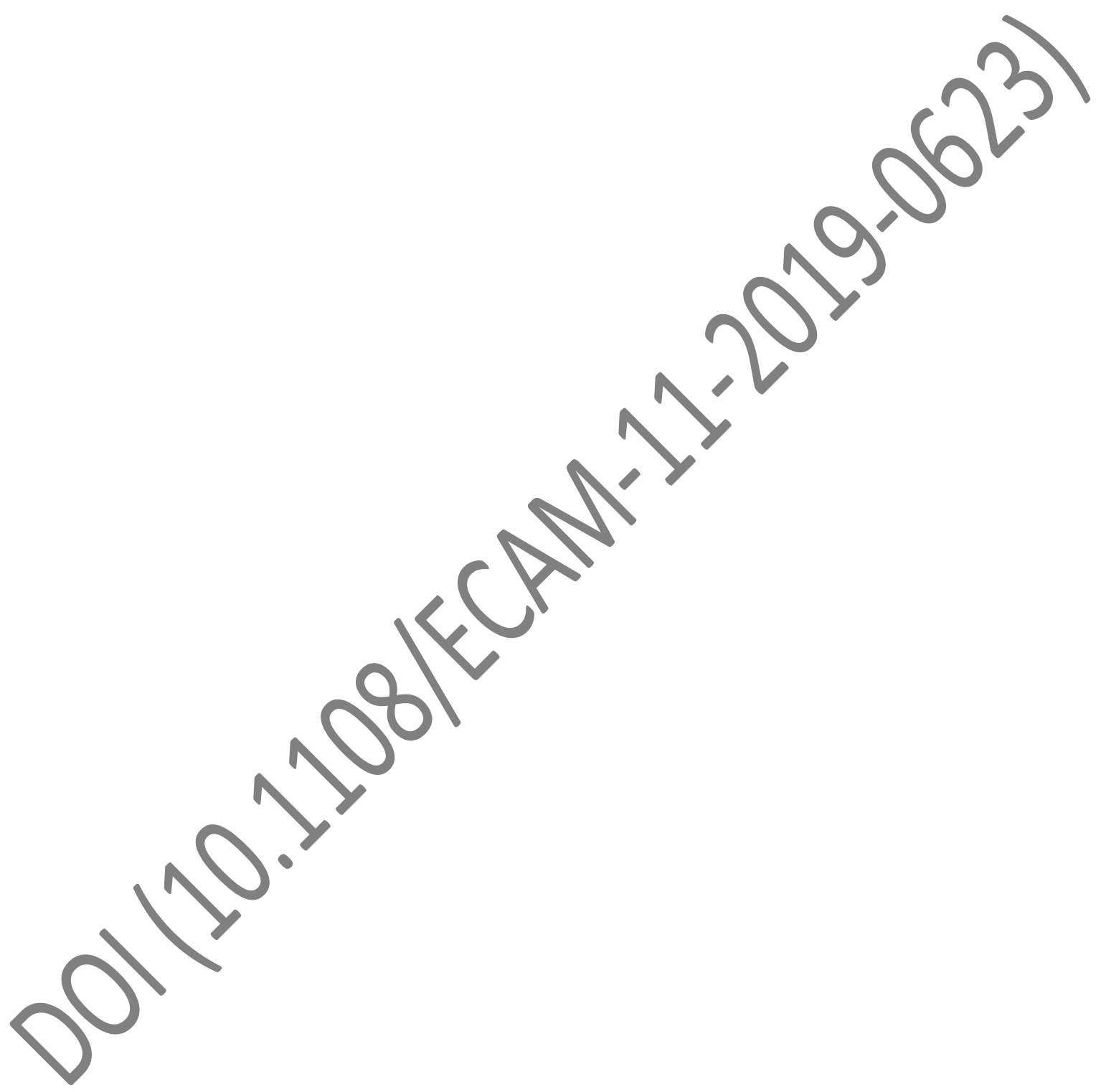


This Manuscript is accepted to be published at ECAM journal DOI (10.1108/ECAM-112019-0623)

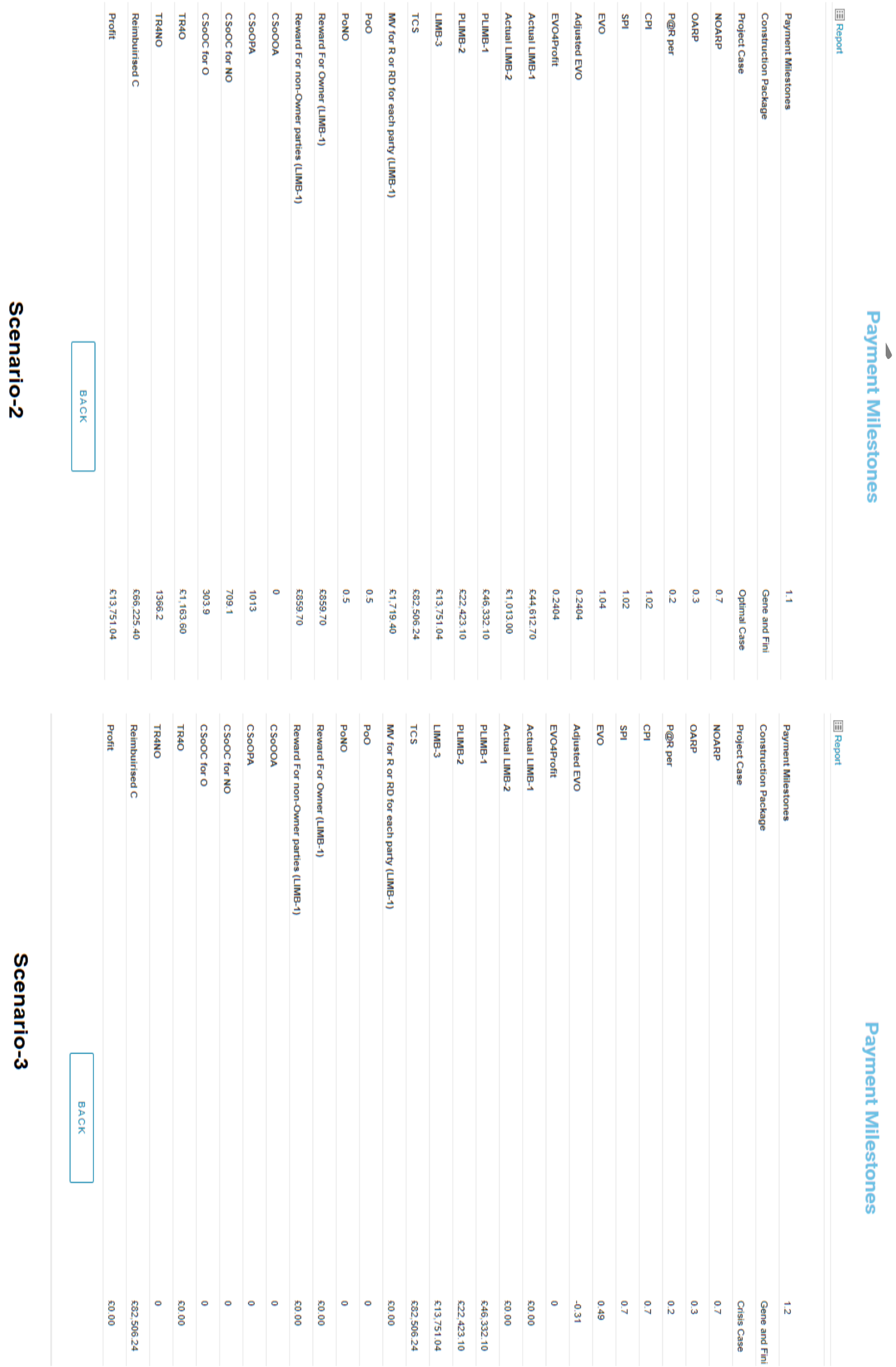

Figure 7.The risk/reward report for scenario 2 and 3. 
This Manuscript is accepted to be published at ECAM journal DOI (10.1108/ECAM-112019-0623)

\subsection{The applicability and integration of BIM and EVM-web system}

506

507

508

509

510

511

512

513

514

515

516

517

518

519

520

521

522

523

In order to show how BIM and EVM-web can be utilised, the presented data in the three scenarios, are illustrated in Figure 8, which shows the BIM dimensions (3D, 4D and 5D) that have been developed for this case study. The project data will be retrieved from these three models, as the case study supports the integration of IPD and BIM. With reference to the 4D model, some works have been completed and milestone 1 is set by the end of week 1 in March. Subsequently, those parties responsible for the performed works should submit their invoices as three separate sections (reimbursed costs, profit and cost saving). Afterwards, the quantity surveyor proceeds all data and applies the proposed equations in theframework for determining risk and rewards for the owner and all non-owner parties. Any party in the core team can easily gain access to the website, therefore, all the information on the achieved monetary value of profit and cost saving will be accessible remotely. Besides, each user can readily check the generic case of the designated package through EVM grid through checking where the EVO is located (it is displayed as a yellow circle). Moreover, the EVM-grid can be utilised as a graphical report of the cost situation for the package and project (see Figure 8). All project parties, therefore, can easily understand and use the displayed information, regardless of their skills. This is seen as a remedial solution to one of the endemic problems affecting IPD, as discussed: lack of skills and core team members coming from various different backgrounds (Allison et al., 2018). 
This Manuscript is accepted to be published at ECAM journal DOI (10.1108/ECAM-112019-0623)
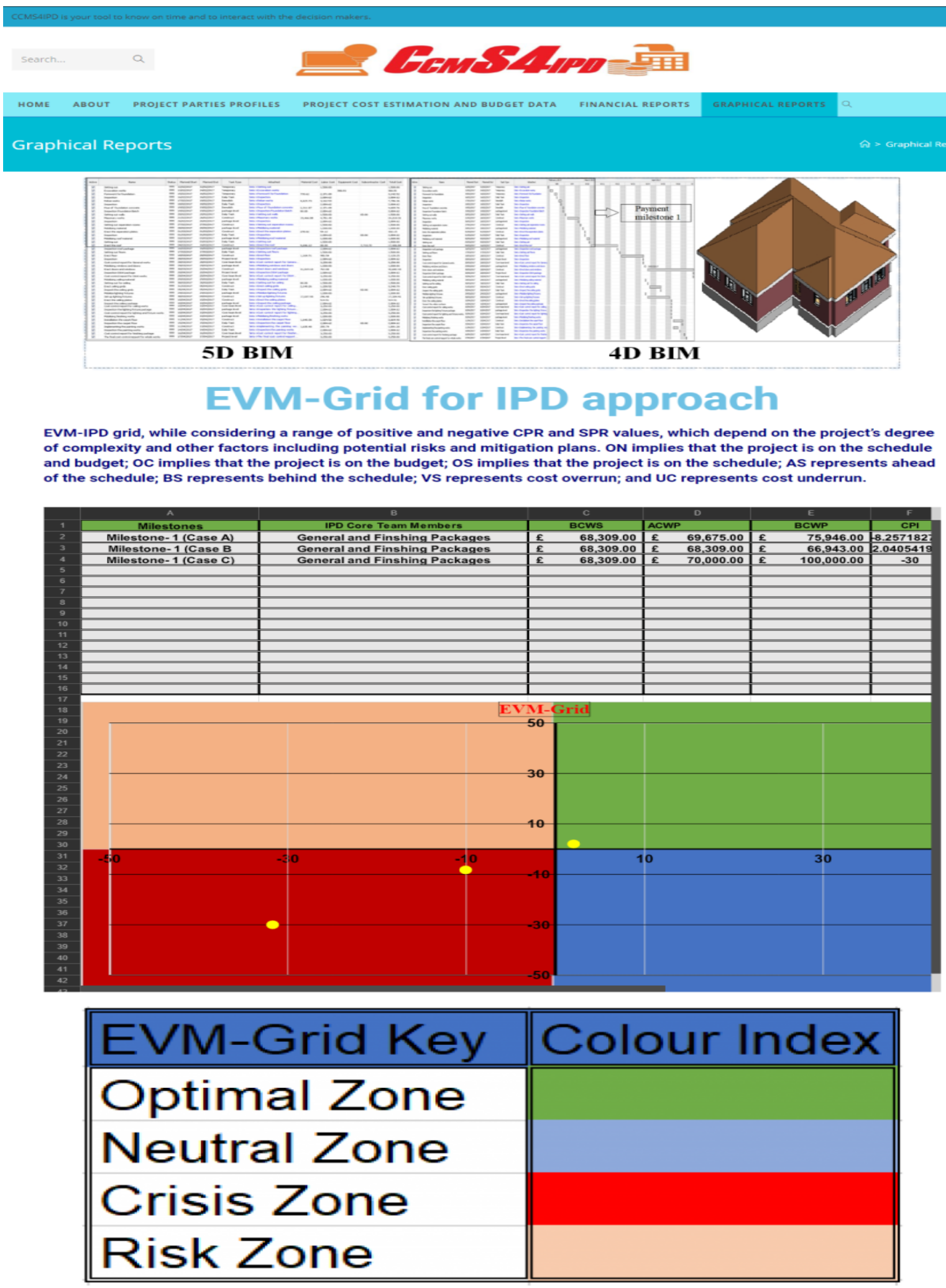

525 Figure 8. The web graphical report 
This Manuscript is accepted to be published at ECAM journal DOI (10.1108/ECAM-112019-0623)

527

528

529

530

531

532

533

534

535

536

537

538

539

540

541

542

543

544

545

546

547

548

549

550

551

This research proposed a comprehensive approach to managing the financial tasks within the IPD approach. The entire IPD's cost management process is studied to identify the weak points as well as potentials, and afterwards set of methods such as ABC, EVM and BIM are integrated into a single/dynamic process.

This study is novel in several ways, that is, the research introduces an innovative grid that locates the CPR, and SPR to provide a picture of project position in terms of cost and schedule. Furthermore, it integrates the EVM-Grid with the ABC estimating method to optimise the cost structure, which is positively reflected in the compensation structure. In addition, the findings present models that deal with risk/reward sharing, through considering new directions, to ensure fair sharing using $\mathrm{ABC}$ sheets and distinguish between the direct and overhead cost saving. For the overhead cost, the framework distinguishes between the sustaining/organisation level and the project level. Additionally, the EVM-Grid has been developed as a web system to allow the participants to easily track their project.

The proposed web-based management system provided an interactive interface to track all the project cost data throughout the entire IPD stages. This enables all parties to check their cost structure for each element (direct, indirect and overhead costs) using the "name of the construction package or the party name' and the entire compensation structure. All data is disclosed, and an authentication information is required (username and password). Moreover, the financial report shows the current value of the profit, cost-saving, and reimbursed costs at each payment milestone by providing the name of parties who implemented the relevant works. Given that, IPD core team members have different backgrounds, the parametric report in the webpage assist the users through a graphical report, to enable all parties to understand the real situation of their work packages.

In practical terms, the findings are invaluable for BIM users, given the practicality and userfriendliness of the proposed models. All the tasks are aligned with the implementation stages 
This Manuscript is accepted to be published at ECAM journal DOI (10.1108/ECAM-112019-0623)

and easily expressed to allow users to collect the required data promptly. The interventions and outcome of this research will be used to develop an automated payment platform based on Hyperledger fabric (blockchain).

\section{References}

ABRISHAMI, S.GOULDING, J.POUR RAHIMIAN, F. and GANAH, A. (2015), "Virtual generative BIM workspace for maximising AEC conceptual design innovation: A paradigm of future opportunities". Construction Innovation, Vol. 15 No. 1. 24-41.

AHMAD, I.AZHAR, N. and CHOWDHURY, A. (2019), "Enhancement of IPD Characteristics as Impelled by Information and Communication Technology". Journal of Management in Engineering, Vol. 35 No. 1.04018055.

AIA. 2007. Integrated Project Delivery: A Guide [Online]. The American Institute of Architects. Available: $\quad$ https://www.aia.org/resources/64146-integrated-project-delivery-a-guide [Accessed 26 June 2018].

AIBINU, A. and VENKATESH, S. (2013), "Status of BIM adoption and the BIM experience of cost consultants in Australia". Journal of Professional Issues in Engineering Education and Practice, Vol. 140 No. 3. 04013021.

ALLISON, M.ASHCRAFT, H.CHENG, R.KLAWENS, S. and PEASE, J. (2018), "Integrated Project Delivery: An Action Guide for Leaders".

ASHCRAFT, H. W. (2012), "The IPD framework". San Francisco, CA: Hanson Bridgett LLP. 1-25.

ASHCRAFT JR, H. W. (2011), "Negotiating an integrated project delivery agreement". Constr. Law., Vol. 31. 17.

BANIHASHEMI, S.TABADKANI, A. and HOSSEINI,M. R. (2018), "Integration of parametric design into modular coordination: A construction waste reduction workflow". Automation in Construction, Vol. 88. 1-12.

CHEUNG, S. O.SUEN, H. C. and CHEUNG, K. K. (2004), "PPMS: a web-based construction project performance monitoring system". Automation in construction, Vol. 13 No. 3. 361-376.

CHOU, J.-S.CHEN, H.-M.HOU, C.-C. and LIN, C.-W. (2010), "Visualized EVM system for assessing project performance". Automation in Construction, Vol. 19 No. 5. 596-607.

DAS, T. and TENG, B.-S. (2001), "A risk perception model of alliance structuring". Journal of International Management, Vol. 7 No. 1. 1-29.

DO, D.BALLARD, G. and TOMMELEIN, I. D. An analysis of potential misalignments of commercial incentives in Integrated Project Delivery and Target Value Design. Proceedings of the 23rd Conference of the International Group for Lean Construction, 2015. 277-286.

EADIE, R.BROWNE, M.ODEYINKA, H.MCKEOWN, C. and MCNIFF, S. (2013), "BIM implementation throughout the UK construction project lifecycle: An analysis". Automation in construction, Vol. 36. 145-151.

ELGHAISH, F.ABRISHAMI, S.ABU SAMRA, S.GATERELL, M.HOSSEINI, M. R. and WISE, R. (2019a), "Cash flow system development framework within integrated project delivery (IPD) using BIM tools". International Journal of Construction Management. 1-16.

ELGHAISH, F.ABRISHAMI, S.HOSSEINI, M. R.ABU-SAMRA, S. and GATERELL, M. (2019b), "Integrated project delivery with BIM: An automated EVM-based approach". Automation in Construction, Vol. 106. 102907.

ELGHAISH, F. A. K.ABRISHAMI, S.HOSSEINI, M. R. and ABU-SAMRA, S. (2020), "Revolutionising Cost Structure for Integrated Project Delivery: A BIM-Based Solution". Engineering, Construction and Architectural Management. 

2019-0623)

FAIRLEY, N.CARRICK, A. and FAIRLY, N. 2005. The casa cookbook, Acolyte science Cheshire.

FISCHER, M. J. A.KHANZODE, A.REED, D. P. and ASHCRAFT, H. W., JR. 2017. Integrating project delivery, Hoboken, New Jersey, John Wiley \& Sons Inc.

GLICK, S. and GUGGEMOS, A. IPD and BIM: benefits and opportunities for regulatory agencies. Proceedings of the 45th ASC National Conference, Gainesville, Florida, April, 2009.

GODDARD, A. and OOI, K. (1998), "Activity-based costing and central overhead cost allocation in universities: a case study". Public Money and Management, Vol. 18 No. 3. 31-38.

HAMLEDARI, H.MCCABE, B.DAVARI, S. and SHAHI, A. (2017), "Automated schedule and progress updating of IFC-based 4D BIMs". Journal of Computing in Civil Engineering, Vol. 31 No. 4. 04017012.

HARTMANN, T.GAO, J. and FISCHER, M. (2008), "Areas of Application for 3D and 4D Models on Construction Projects". Journal of Construction Engineering and Management, Vol. 134 No. 10. 776-785.

HASTAK, M. 2015. Skills and knowledge of cost engineering, AACE International Morgantown (WV.

HOLLAND, N. L. and JR, D. H. (1999), "Indirect Cost Categorization and Allocation by Construction Contractors". Journal of Architectural Engineering, Vol. 5 No. 2. 49-56.

HOLLAND, R.MESSNER, J.PARFITT, K.POERSCHKE, U.PIHLAK, M. and SOLNOSKY, R. (2010), "Integrated design courses using BIM as the technology platform". Integrated design courses using BIM as the technology platform.

HOSSEINI, M. R.MAGHREBI, M.AKBARNEZHAD, A.MARTEK, I. and ARASHPOUR, M. (2018), "Analysis of Citation Networks in Building Information Modeling Research". Journal of Construction Engineering and Management, Vol. 144 No. 8. 04018064.

ILOZOR, B. D. and KELLY, D. J. (2012), "Building information modeling and integrated project delivery in the commercial construction industry: A conceptualstudy". Journal of Engineering, Project, and Production Management, Vol. 2 No.1.23-36.

JACOBSSON, M. and LINDEROTH, H. C. (2010), "The influence of contextual elements, actors' frames of reference, and technology on the adoption and use of ICT in construction projects: a Swedish case study". Construction management and Economics, Vol. 28 No. 1. 13-23.

KHAMOOSHI, H. and ABDI, A. (2016), "Project duration forecasting using earned duration management with exponential smoothing techniques". Journal of Management in Engineering, Vol. 33 No.1.04016032.

KIM, Y.-W. and BALLARD, G. Activity-based costing and its application to lean construction. Proceedings of the 9 th Annual Conference of the International Group for Lean Construction, Singapore, August, 20012001 National University of Singapore.

KIM, Y.-W.HAN, S.-H.YI, J.-S. and CHANG, S. (2016), "Supply chain cost model for prefabricated building material based on time-driven activity-based costing". Canadian Journal of Civil Engineering, Vol. 43 No. 4. 287-293.

LATIFFI, A. A.MOHD, S.KASIM, N. and FATHI, M. S. (2013), "Building information modeling (BIM) application in Malaysian construction industry". International Journal of Construction Engineering and Management, Vol. 2 No. 4A. 1-6.

LEE, S.-K.KIM, K.-R. and YU, J.-H. (2014), "BIM and ontology-based approach for building cost estimation". Automation in Construction, Vol. 41. 96-105.

LI, J.MOSELHI, O. and ALKASS, S. (2006), "Internet-based database management system for project control". Engineering, Construction and Architectural Management, Vol. 13 No. 3. 242-253.

LIN, Y.-C.WANG, L.-C. and TSERNG, H. P. (2006), "Enhancing knowledge exchange through web mapbased knowledge management system in construction: Lessons learned in Taiwan". Automation in Construction, Vol. 15 No. 6. 693-705.

LINTHICUM, D. S. 2003. Next generation application integration: from simple information to Web services, Addison-Wesley Longman Publishing Co., Inc. 

2019-0623)

LIPKE, W.ZWIKAEL, O.HENDERSON, K. and ANBARI, F. (2009), "Prediction of project outcome: The application of statistical methods to earned value management and earned schedule performance indexes". International Journal of Project Management, Vol. 27 No. 4. 400-407.

LU, Q.WON, J. and CHENG, J. C. (2016), "A financial decision making framework for construction projects based on 5D Building Information Modeling (BIM)". International Journal of Project Management, Vol. 34 No. 1. 3-21.

MA, Z.ZHANG, D. and LI, J. (2018), "A dedicated collaboration platform for Integrated Project Delivery". Automation in Construction, Vol. 86. 199-209.

MIGNONE, G.HOSSEINI, M. R.CHILESHE, N. and ARASHPOUR, M. (2016), "Enhancing collaboration in BIM-based construction networks through organisational discontinuity theory: a case study of the new Royal Adelaide Hospital". Architectural Engineering and Design Management, Vol. 12 No. 5. 333-352.

MILLER, J. A. 1996. Implementing activity-based management in daily operations, The University of Michigan, John Wiley \& Sons.

NAENI, L. M.SHADROKH, S. and SALEHIPOUR, A. (2011), "A fuzzy approach for the earned value management". International Journal of Project Management, Vol. 29 No. 6. 764-772.

ORAEE, M.HOSSEINI, M. R.PAPADONIKOLAKI, E.PALLIYAGURU, R. and ARASHPOUR, M. (2017), "Collaboration in BIM-based construction networks: A bibliometric-qualitative literature review". International Journal of Project Management, Vol. 35 No. 7.1288-1301.

OZORHON, B.KARATAS, C. G. and DEMIRKESEN, S. (2014), "A web-based database system for managing construction project knowledge". Procedia-Social and Behavioral Sciences, Vol. 119. 377-386.

PAJARES, J. and LÓPEZ-PAREDES, A. (2011), "An extension of the EVM analysis for project monitoring: The Cost Control Index and the Schedule Control Index". International Journal of Project Management, Vol. 29 No. 5. 615-621.

PÄRN, E. A. and EDWARDS, D. J. (2017), "Conceptualising the FinDD API plug-in: A study of BIM-FM integration". Automation in Construction, Vol. 80. 11-21.

PISHDAD-BOZORGI, P.MOGHADDAM, E.H. and KARASULU, Y. Advancing target price and target value design process in IPD using BIM and risk-sharing approaches. ASSOCIATED SCHOOLS OF CONSTRUCTION ANNUALINTERNATION CONFERENCE, 49th, San Luis Obispo, 2013.

PISHDAD-BOZORGI, P. and SRIVASTAVA, D. 2018. Assessment of Integrated Project Delivery (IPD) Risk and Reward Sharing Strategies from the Standpoint of Collaboration: A Game Theory Approach. Construction Research Congress 2018. New Orleans, Louisiana: American Society of Civil Engineers.

PMI 2013. A guide to the project management body of knowledge (PMBOK ${ }^{\circledR}$ guide), Newtown Square, Pennsylvania, Project Management Institute.

RAHIMIAN, F. P.CHAVDAROVA, V.OLIVER, S. and CHAMO, F. (2019), "OpenBIM-Tango integrated virtual showroom for offsite manufactured production of self-build housing". Automation in Construction, Vol. 102. 1-16.

RAHIMIAN, F. P.IBRAHIM, R. and BAHARUDIN, M. N. Using IT/ICT as a new medium toward implementation of interactive architectural communication cultures. 2008 International symposium on Information Technology, 2008. IEEE, 1-11.

RAHIMIAN, F. P.SEYEDZADEH, S.OLIVER, S.RODRIGUEZ, S. and DAWOOD, N. (2020), "On-demand monitoring of construction projects through a game-like hybrid application of BIM and machine learning". Automation in Construction, Vol. 110. 103012.

ROWLINSON, S. (2017), "Building information modelling, integrated project delivery and all that". Construction Innovation, Vol. 17 No. 1. 45-49.

ROY, D.MALSANE, S. and SAMANTA, P. K. (2018), "Identification of Critical Challenges for Adoption of Integrated Project Delivery". Lean Construction Journal. 
This Manuscript is accepted to be published at ECAM journal DOI (10.1108/ECAM-112019-0623)

TSAI, W.-H.YANG, C.-H.CHANG, J.-C. and LEE, H.-L. (2014), "An Activity-Based Costing decision model for life cycle assessment in green building projects". European Journal of Operational Research, Vol. 238 No. 2. 607-619.

TSAI, W. H. and HUNG, S.-J. (2009), "A fuzzy goal programming approach for green supply chain optimisation under activity-based costing and performance evaluation with a value-chain structure". International Journal of Production Research, Vol. 47 No. 18. 4991-5017.

WANG, K.-C.WANG, W.-C.WANG, H.-H.HSU, P.-Y.WU, W.-H. and KUNG, C.-J. (2016a), "Applying building information modeling to integrate schedule and cost for establishing construction progress curves". Automation in Construction, Vol. 72. 397-410.

WANG, Q.MEI, T.KONG, L. and XIAO, Y. (2016b), "Incentive Compensation Structure for Cost Control of Construction Project Based on IPD-Ish in China". Journal of Construction Engineering and Management.

WEXLER, M. N. (2001), "The who, what and why of knowledge mapping". Journal of knowledge management, Vol. 5 No. 3. 249-264.

ZAHRA KAHVANDI, E. S., AHAD ZARE RAVASAN, AND TAHA MANSOURI (2018), "An FCM-Based Dynamic Modelling of Integrated Project Delivery Implementation Challenges in Construction Projects". Lean construction journal, No. 2018. 63-87.

ZHANG, L.CAO, T. and WANG, Y. (2018), "The mediation role of leadership styles in integrated project collaboration: An emotional intelligence perspective". International Journal of Project Management, Vol. 36 No. 2. 317-330.

ZHANG, L. and LI, F. (2014a), "Risk/reward compensation model for integrated project delivery". Engineering Economics, Vol. 25 No. 5. 558-567.

ZHANG, L. and LI, F. (2014b), "Risk/reward compensation modêl for integrated project delivery". Inzinerine Ekonomika-Engineering Economics, Vol. 25 No. 5. 558-567.

ZIMINA, D.BALLARD, G. and PASQUIRE, C. (2012), "Target value design: using collaboration and a lean approach to reduce construction cost". Construction Management and Economics, Vol. 30 No. 5. 383-398.

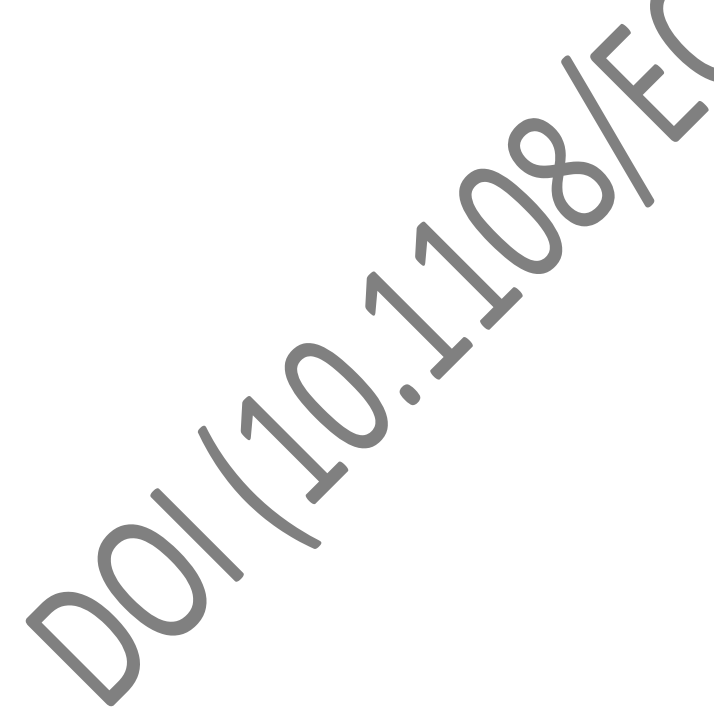

